Theory of Planned Behaviour and Parasuicide: An Exploratory Study

CURRENT PSYCHOLOGY, 22, 247-256.

Rory C. O’Connor ${ }^{\mathrm{a}}$ and Christopher J. Armitage ${ }^{\mathrm{b}}$

Running Head: THEORY OF PLANNED BEHAVIOUR AND PARASUICIDE

Cite article as follows: O'Connor, R.C. \& Armitage, C.J. (2003). Theory of Planned Behaviour and Parasuicide: An Exploratory Study. Current Psychology, 22, 247-256 


\title{
Theory of Planned Behaviour and Parasuicide: An Exploratory Study
}

\begin{abstract}
$\underline{\text { Abstract }}$
Recent evidence suggests that parasuicide (deliberate self-harm) should be considered in terms of 'normal' rather than 'abnormal' behaviour. This study aimed to address this assertion by applying a social cognition model, for the first time, to parasuicidal behaviour. An extended theory of planned behaviour (TPB) model was tested on 55 individuals drawn from hospital and non-hospital populations. Thirty-eight percent of the sample $(\underline{n}=21)$ reported a history of deliberate self-harm. Findings supported the utility of the TPB: attitudes, subjective norm, selfefficacy, moral norm and anticipated affect discriminated significantly between those with and without a history of parasuicide. The extended TPB explained more than $50 \%$ of the variance associated with intentions to deliberately self-harm. These findings have considerable theoretical and practical implications for intervention. Future research should investigate the utility of the TPB employed within a prospective framework.
\end{abstract}




\section{$\underline{\text { Introduction }}$}

Parasuicide, defined as any non-fatal act in which an individual deliberately causes selfinjury or ingests a substance in excess of any prescribed or generally recognised dosage (Kreitman, 1977), represents a significant personal, social and economic problem. For too many years, the rates of parasuicide and completed suicide have been increasing, especially suicide among young men. Despite research attempts, we are no closer to arresting this phenomenon than we were a decade ago. This may be for a number of reasons, however, two issues are probably central. First, suicidal behaviour should be considered along a continuum, as much of the work carried out to date views deliberate self-harm ${ }^{\mathrm{i}}$ and completed suicide as separate phenomena, or at best as overlapping populations. As a result, research into these areas has been polarised to some degree and has not benefited from an integrated standpoint. For example, somewhere in the region of 40 per cent of completed suicides have a history of self-injury, irrespective of whether, at attempt, they intended to kill themselves (O’Connor \& Sheehy, 2000) - for this reason itself suicidal behaviour should be considered in terms of a continuum.

Second, suicidal behaviour remains stigmatised and is still firmly rooted in the domain of 'abnormal' behaviour. At the very best this is unfortunate, and at the worst, this represents a hindrance to (i) research per se, not to mention (ii) those who are vulnerable to suicide, but who will not avail of the existing healthcare services for fear of stigma (O’Connor et al., 2000). Suicidal behaviour, irrespective of how you define normality, should not be considered abnormal. Thus far, research has focused on suicide as a disease, reinforcing the notion that mental illness is a precursor to all suicidal behaviour - it is not. The traditional 'face' of suicidal behaviour is 
changing, it now seems that more of those who kill themselves have not acquired a psychiatric diagnosis or been in contact with the healthcare services (O’Connor et al., 1999).

With the biopsychosocial model in the ascendance, treating suicidal behaviour as the unfortunate end-product in a series of interactions between normal psychological and psychosocial processes is long overdue. To this end, social cognition models have enjoyed a revival in recent years (see Armitage \& Conner, in press a), their underlying premise being that we can identify predictive behaviour patterns, and hence, devise interventions to modify behaviours and thus enhance well-being. Such a paradigm views behaviour, be that engaging in unsafe sexual practices or smoking, as 'normal' behaviour. That they are both 'risk-taking' behaviours, in the same way as suicidal behaviour, is consistently overlooked. They differ only in timeliness of the outcome - suicidal behaviour has a proximal outcome (e.g. admission to hospital / death) whereas smoking or unsafe sexual practices have distal outcomes (e.g. cancer, sexually transmitted disease).

A number of social cognition models have been designed to predict health-related behaviour (e.g., health belief model, protection motivation theory, see Conner \& Norman, 1996). For the purposes of the present study, the theories of reasoned action (Fishbein \& Ajzen, 1975) and planned behaviour (Ajzen, 1991) will be applied to the study of parasuicide. The choice of these models is based on three rationales. First, the theories of reasoned action and planned behaviour have been applied widely in both health and non-health based contexts (see Ajzen, 1991; Armitage \& Conner, in press b). Given that our position regards suicide as one end of a continuum of 'normal' behaviour, these theories provide general models of social behaviour that do not focus on illness. Second, both reviews and empirical comparisons have demonstrated that the theories of reasoned action and planned behaviour have superior predictive power when 
compared with other models of health behaviour (e.g., Armitage \& Conner, in press a; Quine, Rutter, \& Arnold, 1998). Third, Shneidman's (1996) model of suicide behaviour identifies the expression of an intention to commit suicide (however it is perceived by others) as an important part of the process. The ability to predict an individual's intention to engage in deliberate selfharm therefore has considerable implications for suicide prevention.

Within the theory of reasoned action (TRA; Ajzen \& Fishbein, 1980; Fishbein \& Ajzen, 1975), behavioural intention is regarded as the proximal determinant of behaviour. Behavioural intention is regarded as the motivation necessary to engage in a particular behaviour: the greater one's intention to (for example) commit suicide, the more likely one is to actually engage in this act. The predictive power of behavioural intention has been demonstrated in a number of metaanalyses (e.g., Armitage \& Conner, in press b; Randall \& Wolff, 1994; Sheeran \& Orbell, 1998), and many studies use measures of behavioural intention as a proxy for actual behaviour, where such measures would be inappropriate or difficult to obtain (e.g., Abrams, Hinkle, \& Tomlins, 1999; Liao, Shao, Wang, \& Chen, 1999). In turn, behavioural intentions are independently determined by attitudes and subjective norms. Attitudes are positive or negative evaluations of objects or behaviours, and subjective norms are measures of the perceived social pressure to engage (or not) in the behaviour.

The theory of planned behaviour (TPB; Ajzen, 1991) extends the TRA by including measures of perceived behavioural control. Ajzen (1991) argues that perceived behavioural control (PBC) is synonymous with Bandura’s (1997) notion of self-efficacy (i.e., “confidence in one's own ability”). Thus, where individuals believe that a particular behaviour is under their personal control, the more likely they are to both intend to engage in that behaviour, and also to actually perform that behaviour. Several meta-analyses support the inclusion of PBC to extend 
the TRA, both in relation to health behaviours (Godin \& Kok, 1996) and social behaviour in general (Ajzen, 1991; Armitage \& Conner, in press b).

However, in spite of broad support for the TPB, it has been argued that it might be possible to increase the predictive power of the model by incorporating additional variables (e.g., Conner \& Armitage, 1998). Two in particular - moral norm and anticipated affect - are analogous with constructs that have been used to distinguish suicidal sub-types (O’Connor et al., 2000).

Moral norm and anticipated affect have been shown to add to the prediction of intentions, over and above TPB variables (see Conner \& Armitage, 1998; van der Pligt \& de Vries, 1998). Moral norms are operationally defined as, “...personal feelings of...responsibility to perform, or refuse to perform, a certain behavior” (Ajzen, 1991, p. 199). Thus, moral norms are distinct from subjective norms insofar as they are feelings associated with personal norms, rather than the direct social pressure that is exerted by subjective norms. Conner and Armitage (1998) have demonstrated that moral norms account for (on average) an additional $4 \%$ of the variance in intention, over and above the effects of TPB variables (see also Manstead, 2000). Anticipated affect has been included within the TPB to extend the model beyond a purely rational decision making model. More specifically, this construct takes account of how individuals rate they will feel after engaging in a particular behaviour (or not). These anticipated feelings are held to exert motivational significance over individuals, as evidenced by a series of studies by Richard and colleagues (e.g., Richard, van der Pligt, \& de Vries, 1995, 1996), which indicate that anticipated affect accounted for additional variance in behavioural intentions, over and above TPB variables.

The aims of the present exploratory study were twofold: (a) to test the efficacy of the TPB in the domain of parasuicide and hence its efficacy as a potential screening tool; (b) examine 
whether anticipated affect and moral norms contribute additional variance to the prediction of behavioural intentions. Despite the relatively small sample size relative to traditional TPB applications, this study has considerable practical and theoretical utility, if successful. For example, it would add to the growing body of evidence which suggests that "suicide and attempted suicide are actions that are planned and carried out by individuals, involving conscious processes, and they are thus not mere signs of illness and pathology” (Michel \& Valach, 2001, p.230). It would also provide an alternative framework on which to base therapeutic technologies derived from the sphere of normal rather than abnormal psychological functioning.

\section{Method}

\section{$\underline{\text { Participants }}$}

Patients admitted overnight to the acute receiving wards of a Glasgow hospital were considered for inclusion in the study. This included patients presenting with minor physical ailments as well as those presenting with an episode of deliberate self-harm (ICD codes X60-X84). During the study period, 11 parasuicide patients, and 33 hospital controls were tested. This did not represent a consecutive sample but rather reflected the practical limitations of recruiting patients admitted via a general hospital. Eleven non-hospital controls, drawn from an opportunistic sample, were assessed on the same measures as the inpatients (as described in MacLeod et al., 1993). The mean ages of the groups differed significantly (Kruskall-Wallis one way ANOVA, $\mathrm{p}<.05$ ): parasuicides 32.64 yrs ( $S D=11.70)$, hospital controls 41.33 yrs $(S D=12.55)$ and non-hospital controls 29.91 yrs ( $S D=12.65)$. The distribution of gender (27 males and 28 females in total) and marital status was similar for each of the groups. 
Some individuals in the control groups had self-harmed in the past, hence the participants were also classified into 'ever' self-harmers $(\underline{n}=21)$ and 'never' self-harmers $(\underline{n}=34)$. No statistically significant differences were noted across the groups in terms of gender, age or marital status. The mean ages of the 'ever' self-harmers and 'never' self-harmers were (mean $=33.62$ yrs; $\mathrm{SD}=12.44)$ and (39.59 yrs; $\mathrm{SD}=13.29)$ respectively.

\section{$\underline{\text { Measures }}$}

Behavioural intention. Behavioural intention was measured using three items measured on bipolar (-3 to +3) scales: "I intend to deliberately harm myself in the future (definitely do notdefinitely do)”, “I expect I will deliberately harm myself in the future (definitely will notdefinitely will)", and “I want to deliberately harm myself in the future (definitely do notdefinitely do)". The mean of the items made a scale with good internal reliability (Cronbach's $\alpha$ $=.72)$.

Attitude. The global measure of attitude was assessed by taking the mean six responses to the statement, "My deliberately harming myself is...”. This statement was evaluated on 7-point bipolar $(-3$ to +3$)$ scales with the endpoints: bad-good, harmful-beneficial, unpleasant-pleasant, negative-positive, unenjoyable-enjoyable, and useless-useful. The Cronbach's $\alpha$ for the scale was 81.

$\underline{\text { Subjective norm. }}$ Perceived social pressure to deliberately self-harm was assessed using responses to the item, "People who are important to me think I (should not deliberately harm myself-should deliberately harm myself)”. This was measured on a unipolar (+1 to +7$)$ scale.

Self-efficacy. Confidence in one's own ability was assessed using the responses to three items: "I believe I have the ability to deliberately harm myself in the future (definitely do not- 
definitely do), “To what extent do you see yourself as being capable of deliberately harming yourself in the future? (very incapable of harming myself-very capable of harming myself)", and “How confident are you that you will be able to deliberately harm yourself in the future? (not very confident-very confident)”. Cronbach's $\alpha$ indicated good internal reliability for the scale ( $\alpha$ $=.84)$.

Moral norm. Moral norm was measured using three 7-point unipolar scales, all the "strongly disagree-strongly agree” endpoints. The items were: "It would be morally wrong for me to deliberately harm myself”, “Deliberately harming myself goes against my principles”, and “I personally feel I have a moral obligation not to deliberately harm myself”. Cronbach’s $\alpha$ for the scale was .73.

Anticipated affect. Three items were used to measure anticipated feelings following deliberate self-harm. A statement was presented ("If I deliberately harmed myself, I would feel...”), followed by three antonymous adjectives: feeble-strong, tense-relaxed and sad-happy. The scale was internally reliable (Cronbach's $\alpha=.77$ ).

\section{Procedure}

All participants were given a brief introduction outlining the nature of their participation and the study aims. We highlighted the voluntary nature of participation and, in the cases of the hospital participants, patients were assured that non-participation would not interfere with their treatment protocol. Ethical approval was obtained from the University Hospital Trust and University Psychology Department. Demographic details were acquired from hospital records and during the testing procedure. All participants completed the questionnaire, as outlined above, to assess the components of the TPB and additional variables. To enhance anonymity and 
to reduce response bias, all participants were given an envelope to deposit their questionnaire, on completion.

\section{$\underline{\text { Analysis }}$}

In order to test the applicability of the TPB in this area, we adopted two strategies. The first utilised TPB variables to discriminate between cases of parasuicide and hospital and normal controls. The second examined predictive validity: testing the ability of the extended TPB to predict intentions to self-harm.

\section{Results}

Table 1 presents the group means for TPB variables, divided into parasuicide, hospital control and control groups. The data indicate that parasuicides differed significantly from hospital controls on anticipated affect and self-efficacy, such that parasuicides were more likely to rate that self-harm would improve their mood, and that they felt more confident in their ability to harm themselves. Overall, all three groups reported that they did not intend to self-harm in the future, but the parasuicide group differed significantly from both control groups in that they were more disposed to harming themselves in the future. These data show that the TPB usefully discriminates clinical groups.

Insert Table 1 about here 
However, the data presented in Table 1 includes only those participants who presented at hospital for treatment. In the community there are many who self-harm but do not present for treatment. We therefore divided the sample into two groups: those who had never self-harmed (므 $=34)$ and those who had self-harmed at least once in the past $(\underline{n}=21)$. The groups differed significantly on all measured variables (see Table 2). More specifically, prior self-harmers were more positively disposed to self-harming; more likely to intend to self-harm in the future; felt more social pressure to self-harm, and perceived greater self-efficacy with respect to their selfharming. Moreover, prior self-harmers reported that self-harming in the future would make them feel more calm, and that self-harming was less morally wrong. Thus, the data suggest that in the community at large, there may be people that are disposed to self-harm and that the TPB may be a useful tool for identifying them.

Insert Table 2 about here

The second stage of the analysis focused on the predictive utility of the TPB. Table 3 shows intercorrelations between TPB and additional variables. There were significant positive attitude-intention and self-efficacy-intention correlations but not so for subjective norm and intention. The moral norm and anticipated affect-behavioural intention correlations were also not significant, although moral norm was significantly negatively correlated with attitudes, subjective norm and self-efficacy.

Insert Tables 3 \& 4 about here 
Table 4 presents hierarchical regression analysis of extended TPB variables on behavioural intentions. Attitude and subjective norm were entered on step 1. Together, these variables accounted for a significant proportion (33\%) of the variance in intention, although subjective norm was a non-significant predictor. Self-efficacy was entered on step 2, accounting for significant additional variance $\left(\underline{\mathrm{R}^{2} \text { change }}=.15, \underline{\mathrm{p}}<.001\right)$, thus indicating support for the extension of the theory of reasoned action. The inclusion of moral norm and anticipated affect on the final step accounted for an additional 5\% of the variance, with moral norm being the only predictor $\left(\underline{\mathrm{R}^{2} \text { change }}=.05, \mathrm{p}<.05\right)$. The present findings provide support not only for the TPB as applied to parasuicide, but also for the addition of moral norm.

\section{Discussion}

The aims of this study were two-fold: to test the efficacy of the TPB in the domain of parasuicide and hence its efficacy as a potential screening tool; to examine whether anticipated affect and moral norms contribute additional variance to the prediction of behavioural intentions. To our knowledge, this is the first study to apply the TPB to suicidal behaviour.

Findings from this study support the efficacy of the TPB in the domain of parasuicide and support the notion that deliberate self-harm can be explained in terms of 'normal' psychological constructs. All the TPB variables together with anticipated affect and moral norms discriminated between those who had ever self-harmed and those who had never self-harmed. Moreover, TPB variables explained almost $50 \%$ of the variance associated with intention to deliberately self-harm, with moral norm (but not anticipated affect) explaining additional variance. This provides support for our extension of the TPB (see also Conner \& Armitage, 1998; Manstead, 2000). 
The UK government recently identified the reduction of death from suicide as a priority area earmarked for particular attention, it hopes 'to reduce the death rate from suicide and undetermined injury by at least a further sixth by 2010'(Our Healthier Nation, Secretary of State for Health, 1998, p.78). To this end, the present findings afford a new perspective for the study and treatment of suicidal individuals that ought to assist in combating deliberate self-harm and completed suicide. The implications of these findings are considerable - here we focus on two in particular.

The first implication concerns the successful application of a social cognition model (i.e. TPB): this supports our premise that suicidal behaviour ought to be considered within the domain of health as well as clinical psychology (O’Connor \& Sheehy, 2001). This enhances our understanding of the suicidal process, helps to de-stigmatise suicide and roots it firmly within the domain of everyday behaviour thus reducing its taboo status. Moreover, it extends applications of the TPB beyond health behaviours that involve relatively distal health outcomes (e.g., exercise, cigarette smoking) to a behaviour that is both extreme and immediate.

The second major implication is that this study provides a novel framework for identifying and treating suicidal individuals. At-risk patients could be assessed along these variables, effectively screening those who present with 'high-risk' characteristics. In addition to the existing treatment protocols, interventions could be developed to modify individual attitudes and beliefs thereby reducing risk. By way of an example, the present study found that subjective norms and anticipated affect exerted very little influence on parasuicide intentions. In contrast, attitudes and self-efficacy were the dominant predictors of behavioural intention, and might therefore provide useful strategies for intervention. Both self-efficacy and attitudes are rooted in behavioural decision making insofar as they are determined by beliefs concerning the likelihood 
of certain outcomes (see Bandura, 1997; Fishbein \& Ajzen, 1975). Thus, techniques that focus on the restructuring of cognitions (e.g., cognitive behavioural therapy), might be more successful than attempts to focus on feelings or social environment (e.g., psychodynamic approaches). These data are therefore suggestive of the fact that the decision to self-harm may be largely rational, if not logical. Further research is required to investigate these proposals.

Albeit that these findings support the utility of TPB in explaining suicidal behaviour, they ought to be replicated with a larger sample employing a longitudinal study design, to determine whether the TPB can predict those individuals who actually engage in suicidal behaviour in the future. No research to date has been able to do this was any degree of sensitivity or specificity (see Pokorny, 1993). It is alarming that the best predictor of completed suicide is history of previous suicide attempt. Further research is therefore required to identify the variables that mediate the relationship between past behaviour and future behaviour. This type of work has been one of the focuses of research in social cognition models (see Armitage \& Conner, in press a).

In summary, this study has demonstrated that deliberate self-harm, the best predictor of suicide, can be explained within a social cognition framework, specifically that the measurement of attitudes, subjective norm, self-efficacy, moral norms and anticipated affect differentiate, cross-sectionally, those individuals with and without a history of self-harm. The challenge now is to apply the TPB prospectively, and if successful, this will serve as the foundation for developing an attitude-based screening tool for parasuicide. 


\section{References}

Abrams, D., Hinkle, S., \& Tomlins, M. (1999). Leaving Hong Kong?: The roles of attitude, subjective norm, perceived control, social identity and relative deprivation. International Journal of Intercultural Relations, 23, 319-338.

Ajzen, I. (1991). The theory of planned behavior. Organizational Behavior and Human Decision Processes, 50, 179-211.

Ajzen, I., \& Fishbein, M. (1980). Understanding attitudes and predicting social behavior.

Englewood Cliffs, NJ: Prentice-Hall.

Armitage, C. J., \& Conner, M. (in press a). Social cognition models and health behaviour: A structured review. Psychology and Health.

Armitage, C. J., \& Conner, M. (in press b). Efficacy of the theory of planned behaviour: a metaanalytic review. British Journal of Social Psychology.

Bandura, A. (1997). Self-efficacy: The exercise of control. New York: Freeman.

Conner, M., \& Armitage, C. J. (1998). Extending the theory of planned behavior: A review and avenues for further research. Journal of Applied Social Psychology, 28, 1429-1464.

Conner, M., \& Norman, P. (Eds.) (1996). Predicting health behaviour. Buckingham, UK: Open University Press.

Fishbein, M., \& Ajzen, I. (1975). Belief, attitude, intention and behavior: An introduction to theory and research. Reading, MA: Addison-Wesley.

Godin, G., \& Kok, G. (1996). The theory of planned behavior: A review of its applications to health-related behaviors. American Journal of Health Promotion, 11, 87-98.

Kreitman, N. (1977). Parasuicide. Chichester: Wiley. 
Liao, S., Shao, Y. P., Wang, H., \& Chen, A. (1999). The adoption of virtual banking: an empirical study. International Journal of Information Management, 19, 63-74.

MacLeod, A.K., Rose, G.S. \& Williams, J.M.G. (1993). Components of hopelessness about the future in parasuicide. Cognitive Therapy \& Research, 17, 5, 441-455.

Manstead, A. S. R. (2000). The role of moral norm in the attitude-behavior relationship. In D. J. Terry \& M. A. Hogg (Eds.), Attitudes, behavior and social context: The role of norms and group membership (pp. 11-30). London: Lawrence Erlbaum.

Michel, K. \& Valach, L. (2001). Suicide as Goal-directed Action. In K van Heeringen (Ed.). Understanding Suicidal Behaviour. Chichester: Wiley \& Sons.

O’Connor, R.C. \& Sheehy, N.P. (2001). State of the art: Suicidal behaviour. The Psychologist, $14,20-24$.

O'Connor, R.C. \& Sheehy, N.P. (2000). Understanding Suicidal Behaviour. Leicester: BPS Books. ISBN 1854332902

O’Connor, R.C., Sheehy, N.P. \& O’Connor, D.B. (2000). Fifty cases of general hospital parasuicide. British Journal of Health Psychology, 5, 83-95.

O’Connor, R.C., Sheehy, N.P. \& O’Connor, D.B. (1999). The classification of completed suicide into sub-types. Journal of Mental Health, 8 (6), 629-637

Pokorny, A.D. (1993). Suicide prediction revisited. Suicide and Life-threatening Behaviour, 23 (1), 1-10.

Richard, R., van der Pligt, J., \& de Vries, N. (1995). Anticipated affective reactions and prevention of AIDS. British Journal of Social Psychology, 34, 9-21.

Richard, R., van der Pligt, J., \& de Vries, N. (1996). Anticipated affect and behavioral choice. Basic and Applied Social Psychology, 18, 111-129. 
Shneidman, E.S. (1996). The Suicidal Mind. Oxford University Press: New York.

Secretary of State for Health (1998). Our Healthier Nation - A Contract for Health. HMSO:

London.

van der Pligt, J., \& de Vries, N. K. (1998). Expectancy-value models of health behaviour: The role of salience and anticipated affect. Psychology and Health, 13, 289-306. 
Theory of planned behaviour and parasuicide 18

\section{Acknowledgements}

Thanks to Hazel Connery for her assistance at the data collection stage of the study. 
Table 1. Comparisons of Group Means for TPB and Additional Variables: Parasuicide Compared $\underline{\text { With Two Control Groups }}$

\begin{tabular}{llll}
\hline Variables & $\begin{array}{l}\text { Parasuicide } \\
(\underline{\mathrm{n}}=11)\end{array}$ & $\begin{array}{l}\text { Hospital Controls } \\
(\underline{\mathrm{n}}=33)\end{array}$ & $\begin{array}{l}\text { Controls } \\
(\underline{\mathrm{n}}=11)\end{array}$ \\
\hline Anticipated Affect & $3.48(1.67)^{\mathrm{a}}$ & $1.85(1.61)^{\mathrm{b}}$ & $2.33(1.71)^{\mathrm{ab}}$ \\
Attitude & $-2.29(0.81)$ & $-2.68(0.75)$ & $-2.35(1.20)$ \\
Behavioural intention & $-1.33(1.99)^{\mathrm{a}}$ & $-2.81(0.49)^{\mathrm{b}}$ & $-2.33(1.20)^{\mathrm{b}}$ \\
Moral Norm & $5.79(1.62)$ & $5.40(2.11)$ & $5.61(1.58)$ \\
Subjective Norm & $1.00(0.00)$ & $1.42(1.48)$ & $1.09(0.30)$ \\
Self-efficacy & $4.67(2.39)^{\mathrm{a}}$ & $2.21(1.79)^{\mathrm{b}}$ & $3.76(2.58)^{\mathrm{ac}}$
\end{tabular}

Note. Means with different superscripts differ significantly at the .05 level using Newman-Keuls post hoc pairwise comparisons. Re-analysis using Kruskal-Wallis one-way ANOVA, produced identical results. Significant between-groups differences were found for: anticipated affect $\left(\chi^{2}[2]\right.$ $=10.65, \underline{\mathrm{p}}<.01)$, behavioural intention $\left(\chi^{2}[2]=8.45, \underline{\mathrm{p}}<.05\right)$, and self-efficacy $\left(\chi^{2}[2]=10.52\right.$, $\mathrm{p}<.01)$. 
Theory of planned behaviour and parasuicide 20

$\underline{\text { Table 2. Comparisons of Group Means for TPB and Additional Variables: Ever Self-Harmed }}$ Versus Never Self-Harmed

\begin{tabular}{lll}
\hline Variables & Ever Self-Harmed $(\underline{\mathrm{n}}=21)$ & Never Self-Harmed $(\underline{\mathrm{n}}=34)$ \\
\hline Anticipated Affect & $2.86(1.42)$ & $1.92(1.84)$ \\
Attitude & $-2.03(1.10)$ & $-2.85(0.49)$ \\
Behavioural Intention & $-1.57(1.64)$ & $-2.94(0.21)$ \\
Moral Norm & $4.85(1.66)$ & $5.93(1.95)$ \\
Subjective Norm & $1.71(1.82)$ & $1.00(0.00)$ \\
Self-Efficacy & $4.63(2.17)$ & $2.01(1.74)$
\end{tabular}

Note. Groups differ significantly at the .05 level using both parametric and non-parametric

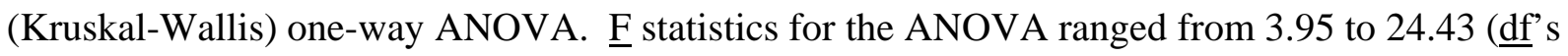

$=1,53$ ); $\chi^{2}$ s for the Kruskal-Wallis tests ranged from 6.85 to 21.89 (ㄷf's = 1). 
Table 3

Zero-Order Correlations Between Measured Variables

\begin{tabular}{|c|c|c|c|c|c|c|}
\hline & Att & SN & SE & $\mathrm{BI}$ & $\mathrm{MN}$ & $\mathrm{A}$ \\
\hline Attitude (Att) & -- & & & & & \\
\hline Subjective Norm (SN) & .22 & -- & & & & \\
\hline Self-Efficacy (SE) & $.48 * *$ & -.09 & -- & & & \\
\hline Behavioural Intention (BI) & $.58^{* *}$ & .06 & $.62^{* *}$ & -- & & \\
\hline Moral Norm (MN) & $-.46 * *$ & $-.30 *$ & $-.25^{*}$ & -.10 & -- & \\
\hline Anticipated Affect (A) & .16 & -.03 & .21 & .16 & -.18 & -- \\
\hline
\end{tabular}


Table 4

Hierarchical Regression Analyses of Expanded TPB Variables

\begin{tabular}{lcccccc}
\hline Step/Predictor & $\underline{\mathrm{R}}$ & $\underline{\mathrm{R}^{2}}$ & $\underline{\mathrm{R}^{2}}$ & $\underline{\mathrm{F}}$ for change & $\beta$ at Step & Final $\beta$ \\
\hline Regression on Intention & & & & & & \\
1. Attitude & .57 & .33 & .33 & $11.49^{* * *}$ & $.60^{* * *}$ & $.44^{* *}$ \\
$\quad$ Subjective Norm & & & & & -.08 & .05 \\
2. Self-Efficacy & .69 & .48 & .15 & $13.27^{* * *}$ & $.45^{* * *}$ & $.47^{* * *}$ \\
3. Anticipated Affect & .73 & .53 & .05 & 2.53 & .05 & .05 \\
$\quad$ Moral Norm & & & & & $.27^{*}$ & $.27^{*}$ \\
\hline * $\mathrm{p}<.05 .{ }^{* *} \mathrm{p}<.01 .{ }^{* * *} \mathrm{p}<.001$. & & & &
\end{tabular}

\footnotetext{
${ }^{\mathrm{i}}$ For the purposes of this paper, deliberate self-harm, parasuicide and self-injury are used interchangeably
} 